sounds on auscultation on the left lung base.

\section{A rare cause of empyema in a non- immunocompromised case and successful combined treatment}

\section{Karnak, D Köksal, S Beder, O Kayacan}

On laboratory analysis his white blood cell count was $20.2 \times 10^{9} / 1$ with $79 \%$ neutrophils. Haemoglobin concentration was $111 \mathrm{~g} / \mathrm{l}$ and erythrocyte sedimentation rate was $68 \mathrm{~mm} /$ hour. Immunoglobulins were in the normal range except for a slightly raised IgG. HIV seropositivity was not found. Chest radiography revealed left pleural effusion. Based on the radiological appearances of the lesion on chest radiography and computed tomography of his thorax (fig 1), a diagnostic procedure was performed.

A 36 year old man was admitted to our hospital with a one month history of pleuritic chest pain on the left hemithorax, productive cough, and fever. He had no known medical problems or drug addiction except a smoking history of 20 pack years.

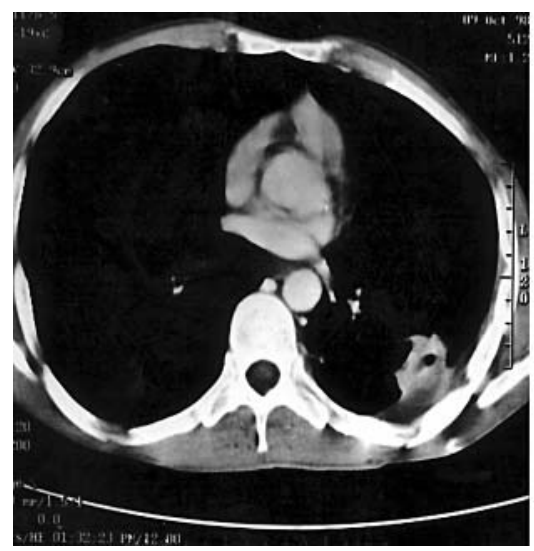

Figure 1 Computed tomograms of the thorax taken at different levels at the start of treatment.

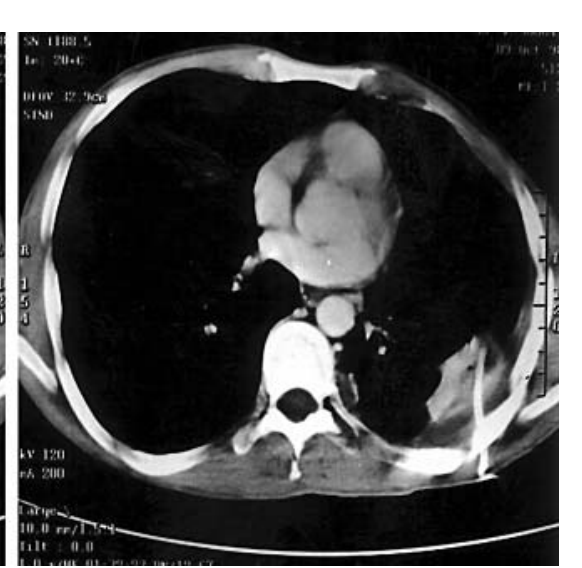

On physical examination, his temperature was $37.6^{\circ} \mathrm{C}$ with pulse rate 104 beats/min, and blood pressure 100/ $60 \mathrm{~mm} \mathrm{Hg}$. His dental hygiene was poor and he had an odontogenic infection. Chest examination revealed dullness to percussion and decreased breath

\title{
QUESTIONS
}

(1) What abnormality was seen on the thoracic computed tomogram?

(2) What was the diagnostic procedure?

(3) What additional tests were/should be performed?

(4) What is the treatment?

Postgrad Med J 2004;80:184.

doi: $10.1136 /$ pgmi.2003.005355q

\section{Authors' affiliations}

D Karnak, D Köksal, S Beder, O Kayacan, Department of Chest Diseases and Tuberculosis, Ankara University Medical School, Ankara, Turkey

Correspondence to: Associate Professor Demet Karnak, Department of Chest Diseases and Tuberculosis, Ankara University Medical School, 06100 Cebeci, Ankara, Turkey; karnak@medicine.ankara.edu.tr

Submitted 14 January 2003

Accepted 16 April 2003 